\title{
La madera y los carbones como testigos del paleo-ambiente, la economía vegetal y el mundo ritual del Perú Precolombino. Metodología y problemáticas
}

Fanny Moutarde*

\begin{abstract}
Resumen
La antracología es el estudio de los carbones de madera encontrados en contextos arqueológicos o en estratigrafías naturales. Su determinación taxonómica permite emprender temas tales como el paleo-ambiente y la utilización de la madera por el hombre en el pasado como materia prima, combustible o herramienta litúrgica. A pesar del poder informativo de los carbones y de su evidente presencia en sitios arqueológicos peruanos, sobre todo costeños, la antracología no se ha desarrollado en Perú todavía. Este artículo pretende dar a conocerla, presentando en primer lugar un historial de esta disciplina; en segundo lugar, lo que son la madera y los carbones; en tercer lugar, cómo se obtienen los datos y; finalmente, las problemáticas que se pueden abordar con un estudio antracológico.
\end{abstract}

\section{Palabras claves}

Carbón, madera, antracología, paleo-ambiente, economía vegetal, metodología.

\section{Summary}

Anthracology is the study of wood charcoals found in archaeological contexts or in natural stratigrafies. The taxonomical determination of the wood charcoals lets deal with issues like palaeo-environment and the use of wood as raw material, fuel or liturgical tool by the past societies. In spite of the high informative potential of wood charcoals and their abundance on the Peruvian archaeological sites, particularly the coastal ones, anthracology is not welldeveloped in Peru. As such, this article introduces the anthracological discipline, presenting, firstly, its historical background ; then defining what "wood" and "wood charcoals" refer to ; thirdly, explaining the methodology of sampling and study of anthracological material ; lastly, the problematics that could be tackled with an anthracological study would layed out.

\section{Keywords}

Wood charcoals, wood, anthracology, palaeo-environment, vegetal economy, methodology.

* Correo electrónico: fannymoutarde@hotmail.com. Instituto Francés de Estudios Andinos. 


\section{Introducción}

Los sitios arqueológicos peruanos, sobre todo costeños, revelan a menudo restos de madera o de carbón de madera ${ }^{1}$. Hasta la fecha, han llamado poco la atención, salvo en el caso de hallazgos de estatuas o cuando se trata de fechar un contexto. Por lo tanto, son los vestigios de utensilios, instrumentos, elementos de construcción, objetos, combustible, es decir, de ecofactos o artefactos que el hombre usaba y sigue usando en su vida cotidiana, laboral o espiritual. En otras regiones del mundo son objeto de mucho cuidado por parte de los arqueólogos y juegan un papel importante en los estudios paleo-ambientales, particularmente los de "site catchment". Desarrollando una metodología adecuada y herramientas apropiadas, el estudio de maderas (xylología) o de carbones (antracología) encontrados en contexto arqueológico, puede contribuir al conocimiento del paleo-ambiente, de la economía vegetal y, en cierta medida, del mundo ritual de las sociedades precolombinas. Por ahora, en la arqueología peruana, la falta de una información básica sobre la manera de colectar carbones durante la excavación, el cómo y el por qué hacerlo, ha perjudicado tales estudios. Este artículo se propone llenar en parte este vacío presentando datos respecto a la metodología de muestreo y de análisis de maderas y carbones, a los principales esquemas interpretativos de la antracología y a las problemáticas que permite abordar. Básicamente se hablará de la antracología, ya que se trata de una disciplina paleoambiental de pleno derecho, a diferencia de la xylología.

\section{Historia}

"Antracología" proviene del griego anthrax, que significa carbón ardiente. Hace referencia al estudio de carbones de madera encontrados en sitios arqueológicos o en estratigrafías naturales. Es totalmente distinto de los análisis de Carbono 14. Se basa en la determinación taxonómica de las muestras por la observación bajo microscopio de su estructura anatómica interna, comparándola con la de maderas actuales.

La antracología nace en Europa a fines del siglo XIX cuando se despierta el interés por el potencial informativo de los carbones arqueológicos encontrados en los sitios palafitos y en las estructuras de combustión de los sitios prehistóricos. En esta época, los carbones eran montados en láminas para ser observados por transparencia con un microscopio de luz transmitida (la luz atraviesa el objeto observado). Sin embargo, pocos carbones eran estudiados porque el tratamiento preliminar de preparación de láminas era largo y tedioso. El real desarrollo de la disciplina empezó entre las décadas de 1960 y 1970 en Europa, gracias a la utilización del microscopio de luz reflejada (la luz viene de arriba y ésta es reflejada por el objeto opaco observado) que permite observar mucho más carbones sin tratamiento preliminar, solamente rompiendo el carbón a mano. Desde hace unos 20 años, la disciplina se desarrolla y se amplía al nivel metodológico y geográfico (Western 1963; Vernet 1973; Chabal et al. 1999; Thiébault 2002).

En América del Sur, la antracología se manifiesta de manera aislada básicamente en Brasil (Scheel-Ybert 1998, 2002), Chile (Solari 1993, 2000), Guyana (Tardy 1997), Argentina (Marconetto 2002) y Tierra de Fuego (Piqué i Huerta 2002).

En el Perú muy pocos estudios antracológicos han sido llevados a cabo dentro de proyectos arqueológicos. El primero fue aplicado por D. Pearsall (1980) en el marco del estudio del material arqueobotánico del sitio de Pachamachay (épocas tardías, valle alto de Mantaro). El segundo fue ejecutado por G. Weir y P. Dering (1986)

\footnotetext{
1 En este artículo, la palabra carbón siempre hará referencia a "carbón de madera", excluyendo cualquier otro tipo de carbón.
} 
sobre carbones procedentes del sitio de "La Paloma" (Período precerámico, valle de Chilca). El tercero fue realizado por C. Hastorf (1990, 2005) y es un estudio comparativo a nivel etnológico, arqueológico y etnohistórico de la utilización del combustible en el valle del Marañón. Salvo el artículo de C. Hastorf (2005), los demás estudios son básicamente cualitativos y no siguen una metodología precisa. Desde el 2002, venimos trabajando en diferentes sitios del valle de Lurín (costa central), tales como Pampa Chica (Período Horizonte Temprano, Dulanto 2002), Pachacamac (Intermedio TempranoConquista, Eeckhout 2004), Pueblo Viejo (Horizonte Tardío, Makowski 2002), con el objetivo de desarrollar una metodología de trabajo en relación con temas precisos de estudio, tales como la reconstitución del paleo-paisaje vegetal o la gestión del recurso leñoso por las sociedades del pasado (Moutarde 2002, 2005, 2006).

Se puede explicar la escasez de estudios antracológicos en Perú por varias razones. Para empezar, no existía hasta ahora una colección de referencia o un atlas anatómico de las especies leñosas peruanas (Moutarde 2006). Sin ello, es imposible trabajar. Luego, no se conoce el potencial informativo de los carbones, porque existen muy pocos especialistas en esta disciplina que expliquen a que tipo de información se puede llegar con carbones. Las problemáticas de investigación arqueológica en el Perú se orientan más hacia asuntos cronológicos o de atribución cultural que a la economía vegetal o el ambiente del pasado. Como resultado, los carbones siguen siendo recogidos durante las excavaciones cuando se trata de fechar un contexto o cuando se observan concentraciones de material carbonizado, pero no de la manera adecuada para permitir un estudio antracológico válido.

\section{La madera y los carbones Material considerado}

iSobre que forma se encuentra la madera en el contexto arqueológico?
La madera se encuentra en los sitios arqueológicos, o en estratigrafías naturales, en forma desecada (medios áridos), empapada (sitios lacustres), crío conservadas (glaciares), carbonizada (fogones, basurales), petrificada, mineralizada (madera impregnada de sales minerales) u oxidada (con óxidos metálicos). En todos los casos, las estructuras anatómicas internas de la madera están conservadas, aunque un poco alteradas.

En el Perú, la madera se conserva sobre todo por desecación (en la costa desértica) o carbonización. El clima desértico de la costa favorece la conservación de los vegetales y de los carbones, mientras la humedad, los microorganismos y la naturaleza del suelo selvático impiden la conservación de restos orgánicos.

\section{¿Que es un carbón?}

Un carbón de leño es el resultado de una combustión incompleta. Durante su combustión, una madera pierde entre el 70 y 80 \% de su sustancia, bajo forma de agua, gases y cenizas. La combustión empieza con la ayuda de calor exterior (fase endotérmica). A partir de los $350^{\circ} \mathrm{C}$, la madera se basta consigo misma para continuar la combustión (fase exotérmica), o sea que la temperatura se eleva de manera espontánea. Llegando a los $500^{\circ} \mathrm{C}$, si el aporte exterior de oxígeno se detiene, la combustión se para y la madera se queda en estado de carbón. Esta es la etapa de calcinación. Si la combustión continúa, la madera se consume por completo y se vuelve cenizas. Un carbón conserva la anatomía interna de la madera con algunas alteraciones como el adelgazamiento de las paredes de las células (debido a la pérdida de agua, gases y cenizas), la vitrificación (debido al mal estado de la madera antes de la carbonización), la fisura (debido al retracto diferencial de los productos volátiles durante la combustión), que no impiden, sin embargo su determinación la mayor parte de los casos (Chabal et al. 1999, Chabal, 1997). 
Las categorías de muestras

En contexto arqueológico, se encuentran diferentes tipos de muestras: a) el carbón que puede provenir de fogones domésticos, de fogones de actividades especializadas (metalurgia, cerámica), de basurales, del incendio de la arquitectura (postes, techos), de sepulturas, de lugares de culto; puede ser también dispersado en las capas de ocupación humanas; b) los artefactos humanos hechos con madera, como las herramientas (agujas, varillas, bastones), los elementos de arquitectura (postes), las esculturas, las ofrendas funerarias, los objetos de la vida cotidiana (vasos, platos); c) la madera no trabajada, que puede ser el residuo de la tala de los artefactos, materia prima por artefactos o combustible potencial.

\section{La determinación de la madera}

Mas allá de que se trate de madera o de carbón, la determinación taxonómica se hace del mismo modo: Por comparación de la anatomía interna de los especímenes arqueológicos con la de especies leñosas actuales conocidas. Entonces, para determinar las maderas arqueológicas, es necesario conocer primero las maderas actuales. Esto parte de un supuesto: La anatomía de la madera de las especies no ha cambiado con el tiempo a la escala de tiempo considerada, es decir, los principios del Período Cuaternario.

Los criterios de determinación de la madera

Cada madera tiene una estructura y organización propia que permite reconocerla. Para llegar a una determinación se observan sus aspectos macroscópicos y microscópicos.

Los aspectos macroscópicos de la madera (color, textura, densidad), se observan y dan una primera idea, pero no son suficientes para llegar a una determinación precisa. En el caso de maderas arqueológicas, estas características son difíciles de apreciar por evidentes problemas de conservación. Por ejemplo, los colores cambian con el tiempo y según el ambiente en el cual se encuentra conservada la pieza.

Al nivel microscópico, la madera se mira según tres cortes, conocidos como los tres cortes anatómicos de la madera (Fig. 1), que permiten observar su estructura, es decir, los elementos que la componen y cómo se organizan entre sí. Son los elementos de conducción (vasos, fibrotraquéidas), de sostén (fibras) y de reserva (parénquima, radios). Los tres cortes son: a) corte transversal que se hace perpendicularmente al tronco. Es el primero que se observa porque reúne una gran cantidad de informaciones que, por lo general, permiten atribuir la muestra a una familia; b) corte longitudinal tangencial que se hace perpendicularmente al transversal, en el sentido de las fibras, cortando perpendicularmente los radios y; c) corte longitudinal radial es también perpendicular al transversal, pero sigue el sentido de los radios. Aún cuando cada especie es única, la descripción de estos tres cortes provee los elementos que permiten su determinación.

Según el estado de conservación de la muestra, su tamaño y la disponibilidad de datos sobre las maderas de la zona de origen del ejemplar, la determinación taxonómica puede llegar al nivel de familia, género o especie. El taxón ${ }^{2}$ queda determinado con su nombre científico para evitar las confusiones inherentes al uso de nombres vernaculares. Por ejemplo, el frutal conocido como guayaba se designa como Psidium guajava L.; familia: Myrtaceae; género: Psidium; especie: Psidium guajava; L.: Linné, nombre del botánico que fue el primero que nombró la especie. La determinación tiene que ser rigurosa. Si se presu-

\footnotetext{
2 La palabra "taxón" se refiere a cualquier unidad de la clasificación de los seres vivos -incluyendo las plantas- como por ejemplo, la variedad, la especie, el género o la familia.
} 


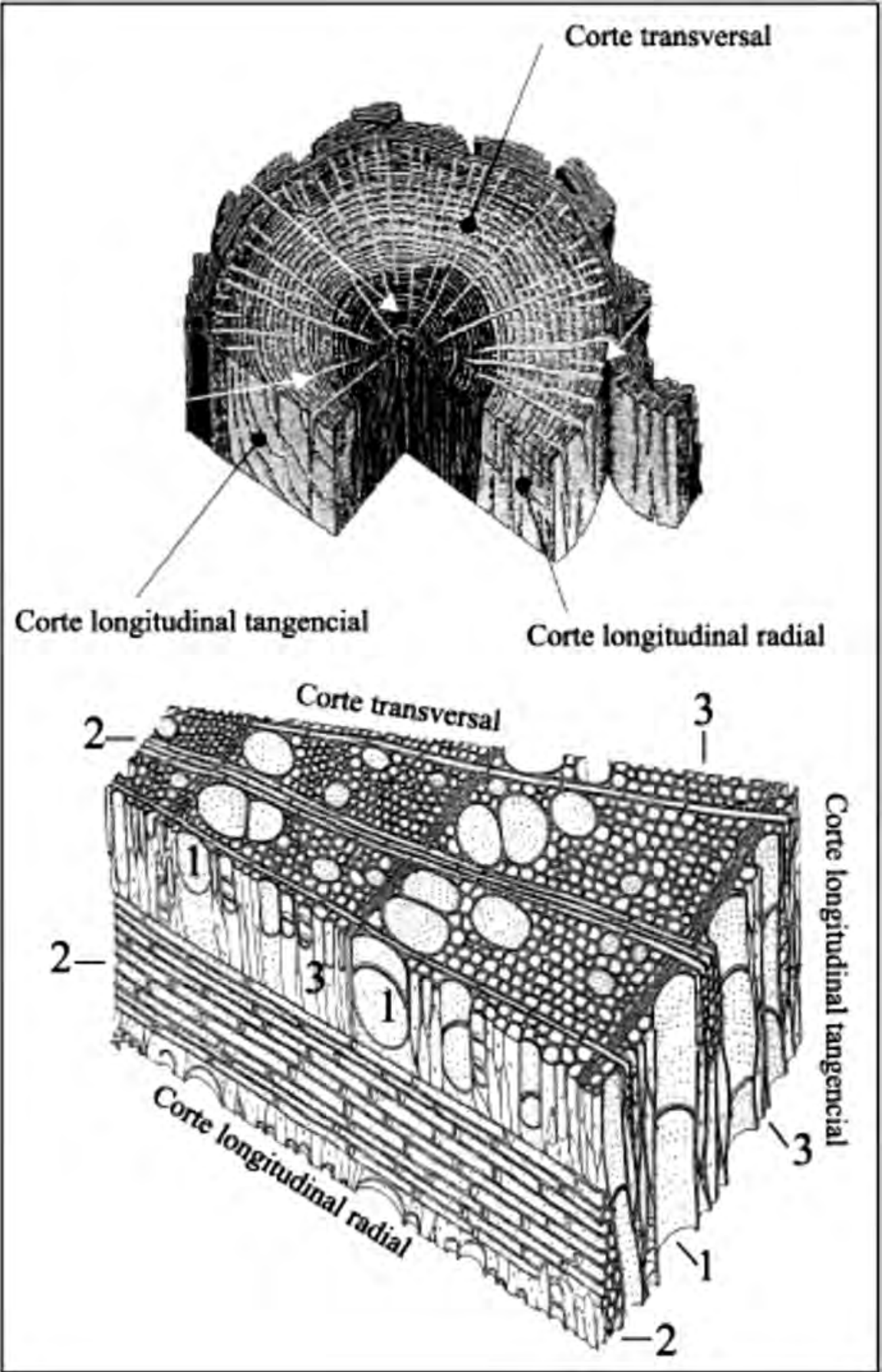

Figura 1. Los cortes anatómicos y los elementos principales de la madera (basado en Raven et al. 2000). 1) vasos; 2) radios; 3 ) fibras. 
me fuertemente que se trata de una especie, pero que faltan algunos criterios diagnósticos, se coloca cf. (de confere en latín) antes del nombre. Por ejemplo, cf. Psidium guajava.

\section{Las colecciones de referencia}

Idealmente, la determinación de las maderas y de los carbones arqueológicos se hace con dos herramientas: Una colección de referencia de maderas actuales, carbonizadas o no, y un atlas (fotos y descripciones) de las especies locales, siempre y cuando exista.

Las colecciones de referencia de maderas actuales se constituyen por la colecta de muestras de árboles vivos que se pueden determinar por observación de sus hojas, flores y corteza. Se recogen partes del tronco, de la raíz y de las ramas, en diferentes lugares y ecosistemas, porque la anatomía de una misma especie puede variar mucho según su ubicación dentro del árbol y según su entorno natural (clima y suelo). Se necesitan varios especímenes de una misma especie para tener una colección válida.

Se puede tratar de una colección de referencia de maderas (xiloteca) o de una colección de referencia de carbones (antracoteca). Una xiloteca está constituida por paralelepípedos de maderas que permiten ver sus aspectos macroscópicos y/o por láminas montadas de madera que permiten observar sus elementos microscópicos. A partir de un cubo de $1 \mathrm{~cm}$ de lado, se hacen cortes finos de los 3 planos anatómicos de la madera con un micrótomo. Después de varios tratamientos químicos sobre los cortes, se preparan láminas montadas que se observan al microscopio de luz transmitida (que atraviesa lo transparente).

La antracoteca está constituida por muestras de carbones obtenidas de la manera siguiente: La madera está envuelta en un papel de aluminio $^{3}$ y colocada en un horno. Se la deja 40 minutos a $400^{\circ} \mathrm{C}$, tiempo y temperatura sufi- cientes para que la madera se carbonice (ScheelYbert 1998).

Luego, el carbón se coloca en una cajita de plástico donde están escritos sus datos referenciales (nombre, número de inventario, lugar de origen, fecha de colecta, etc.). Se observan los carbones con un microscopio electrónico de luz reflejada (la luz esta parcialmente absorbida por la muestra y luego reflejada), fondo oscuro/fondo claro, con aumentos x 50 hasta x1000, también conocido como microscopio metalúrgico. El atlas se hace a partir de la colección de referencia. Consiste en descripciones escritas y fotos de los cortes anatómicos de cada especie (Fig.2).

Hasta ahora, para el Perú, solo existían atlas que analizaban la madera, mayormente selváticas, como potencial fuente comercial (Acevedo Mallque \& Kikata 1994; Détienne \& Jacques 1983). Estos atlas no son de gran ayuda para el estudio del material procedente de la costa o sierra. Pero las cosas empiezan a cambiar. Desde el 2002, venimos armando una colección de referencia de leños - arbustos y árboles - de las vertientes occidentales de los Andes peruanos, a partir de la cual hemos producido un atlas antracológico que reúne 85 de las especies leñosas más representativas de esta área (Moutarde 2002, 2005, 2006). C. Hastorf (2005) presenta fotos de 12 especies serranas.

\section{La obtención de datos \\ Métodos de muestreo}

\section{Parala madera}

En general, se trata de objetos aislados como postes, objetos o esculturas. Lo ideal es sacar un cubo de $1 \mathrm{~cm}$ de lado del artefacto o ecofacto a estudiar. Es factible cuando se trata de madera no trabajada, o si el objeto está tan malogrado que se deshace solo. Pero en general, la determi-

\footnotetext{
3 El envolver la muestra en papel aluminio limita el aporte en oxígeno hasta la madera, impidiendo su combustión total que dejaría solo cenizas.
} 




Figura 2. Ejemplo de una lámina de un atlas antracológico. Aliso (Alnus acuminata). 1: corte transversal $x 200$; 2: corte longitudinal tangencial $x 100$; 3 : corte longitudinal radial $x 500$.

nación se practica sobre objetos a los cuales no se puede substraer tanta materia, como las piezas de museos. En este caso se sacan láminas finas de madera, con la ayuda de una navaja de afeitar, del interior de las ranuras naturales o de partes del objeto lo menos expuestas a la vista. La idea es alterar al mínimo la integridad del objeto.

\section{Para el carbón}

El papel del arqueólogo en el muestreo del carbón es sumamente importante porque son los contextos arqueológicos los que dan a entender cuál fue la causa de la carbonización de la madera y a qué procesos de dispersión y de tafonomía fue sometido el material antracológico. La naturaleza de los contextos arqueológicos (fogón, basural, residuos de incendios) indica cuál es el valor informativo del carbón recogido.

Si los carbones son residuos de madera de construcción (postes, vigas) o de objetos (keros, esculturas), antes de tomar una muestra se observan, miden e interpretan los diferentes trozos en conexión. En este caso, un fragmento es suficiente para el análisis porque todos los elementos son parte de una pieza inicial.

Si son relieves de combustible, por lo general, o se encuentran dispersos básicamente en las capas de ocupación o en los basurales, o se hallan concentrados en fogones. En el caso del material disperso, es preciso zarandear el sedimento que sale de los niveles arqueológicos, mientras que en el caso del material concentrado, se puede recoger los carbones con la mano.

\section{Tamizado y separación}

No existe una norma rígida para tomar una muestra de carbones o un número preciso de litros de sedimento que hay que zarandear. Depende sobre todo de la riqueza de la capa del material. Si la capa tiene una alta concentración de restos, no es necesario tamizar muchos litros, tal vez 3 litros son suficientes. Para saberlo se hace una prueba de tamizado. Tamizando una unidad de volumen (un balde, por ejemplo), se observa la cantidad de fragmentos recuperados y luego se deduce cuántos litros es preciso zarandear para alcanzar un número de carbones lo suficiente como para realizar un estudio antracológico (ver infra).

Cuando el sedimento arqueológico es de tipo arenoso o suelto, se recomienda zarandear al 
seco, es decir, con un tamiz, sin tratamiento particular. Si el sedimento es arcilloso o compacto, es preferible usar un sistema de tamizado con agua o, si se puede, una máquina de flotación. En efecto, los carbones, como los otros restos orgánicos (semillas, coprolitos), se quedan atrapados en la tierra arcillosa y no se ven a simple vista. El agua permite liberarlos de su matriz de barro y recuperar una mayor cantidad de ejemplares que con un tamiz tradicional.

La malla indicada para recuperar los carbones durante el proceso de excavación es de 4 $\mathrm{mm}$. Si el material no está muy bien conservado, debe ser de $2 \mathrm{~mm}$. Más fina no es necesario, salvo que realmente sean pocos los restos, porque los carbones que se recogen con mallas pequeñas $(0.8 \mathrm{~mm})$ son mayormente residuos de fragmentación de carbones más grandes. Ya se demostró que los carbones de menos de $4 \mathrm{~mm}$ no dan más informaciones que los de más de $4 \mathrm{~mm}$ (Chabal 1997). Si un carbón de $4 \mathrm{~mm}$ tiene bastantes probabilidades de reunir los elementos diagnósticos de una madera, no es el caso para un carbón de menos de $0,8 \mathrm{~mm}$.

La etapa final es la separación de los residuos de carbón del tamiz. Se embolsa el residuo del tamizado y luego se separan los carbones y otros macro-restos (semillas, huesos de pescado o de micro-mamíferos) con una pinza, bajo una lupa binocular si la hay o a simple vista. La separación directamente en el tamiz no es conveniente porque induce a una recuperación de los restos más visibles con exclusión de los especímenes más pequeños que también tienen un fuerte potencial informativo.

\section{Métodos de análisis (Fig. 3)}

La observación del material

Las muestras de madera en forma de cubo se observan con el microscopio de luz reflejada fondo claro/fondo oscuro, mientras que las muestras montadas en láminas se observan con el microscopio de luz transmitida. Las muestras de carbón se observan una a una con un microscopio de luz reflejada fondo claro/fondo oscuro, con un aumento de 50x hasta $1000 \mathrm{x}$. A simple vista se reconoce el sentido de la madera y enseguida se corta, según los tres cortes anatómicos, para observar las estructuras de la madera. Se rompe con la mano o se corta con una hoja de afeitar. En algunos casos se utiliza el microscopio electrónico de barrido para tener más profundidad de campo y tomar fotografías más nítidas.

\section{Determinación}

Se comparan las muestras arqueológicas con las maderas actuales (colección de referencia, atlas) hasta llegar a una determinación, cruzando los rasgos anatómicos resaltantes del espécimen observado.

\section{En el caso de carbones dispersos o concentrados Conteo}

Por cada contexto estudiado, se cuentan los fragmentos y no el volumen o el peso, por taxón. No hay un número estándar de carbones para analizar. Sin embargo, una muestra de menos de 30 especímenes no tiene representatividad estadística. Luego, la curva esfuerzo-rendimiento ayuda a decidir a seguir o parar el estudio del material antracológico de un contexto (Fig. 4). Se trata de un gráfico en el cual las ordenadas muestran el rango de las especies nuevamente encontradas y las abscisas el rango del número de carbones estudiados. En un principio, la curva sube rápidamente porque aparecen la mayoría de las especies, pero luego empieza a suavizarse antes de estabilizarse en forma horizontal. Esta estabilización indica que el número de fragmentos que es necesario estudiar para conseguir una nueva especie, es juzgado como demasiado elevado y no rentable para seguir con el análisis. En las zonas temperadas ocurre en promedio al nivel de los 250-300 carbones estudiados (Chabal 1997), en el Brasil tropical a los 200-300 (ScheelYbert 2002); en Perú, queda para estudiar. 


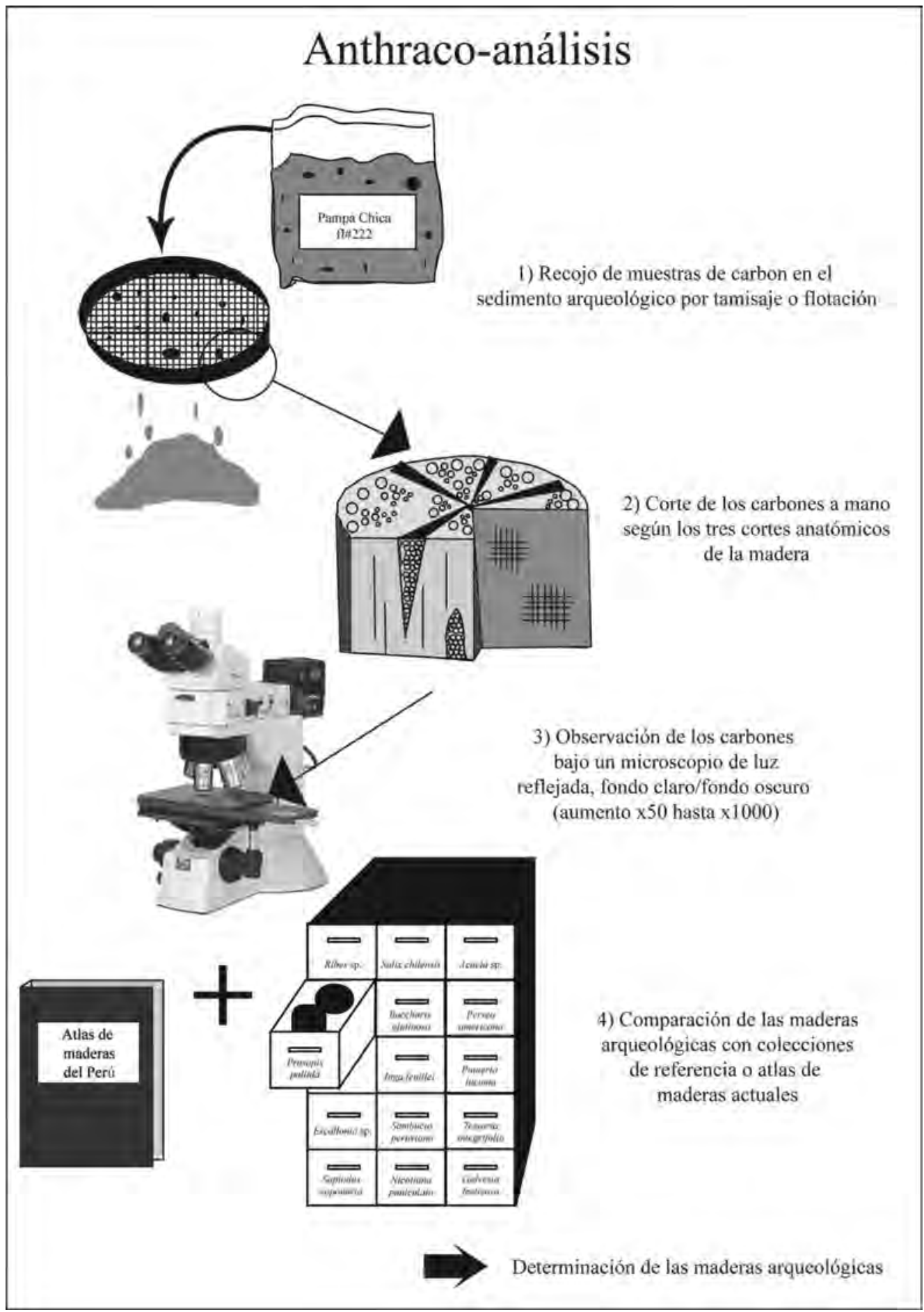

Figura 3. Esquema recapitulativo de la antraco-análisis (basado en Delhon 2005). 


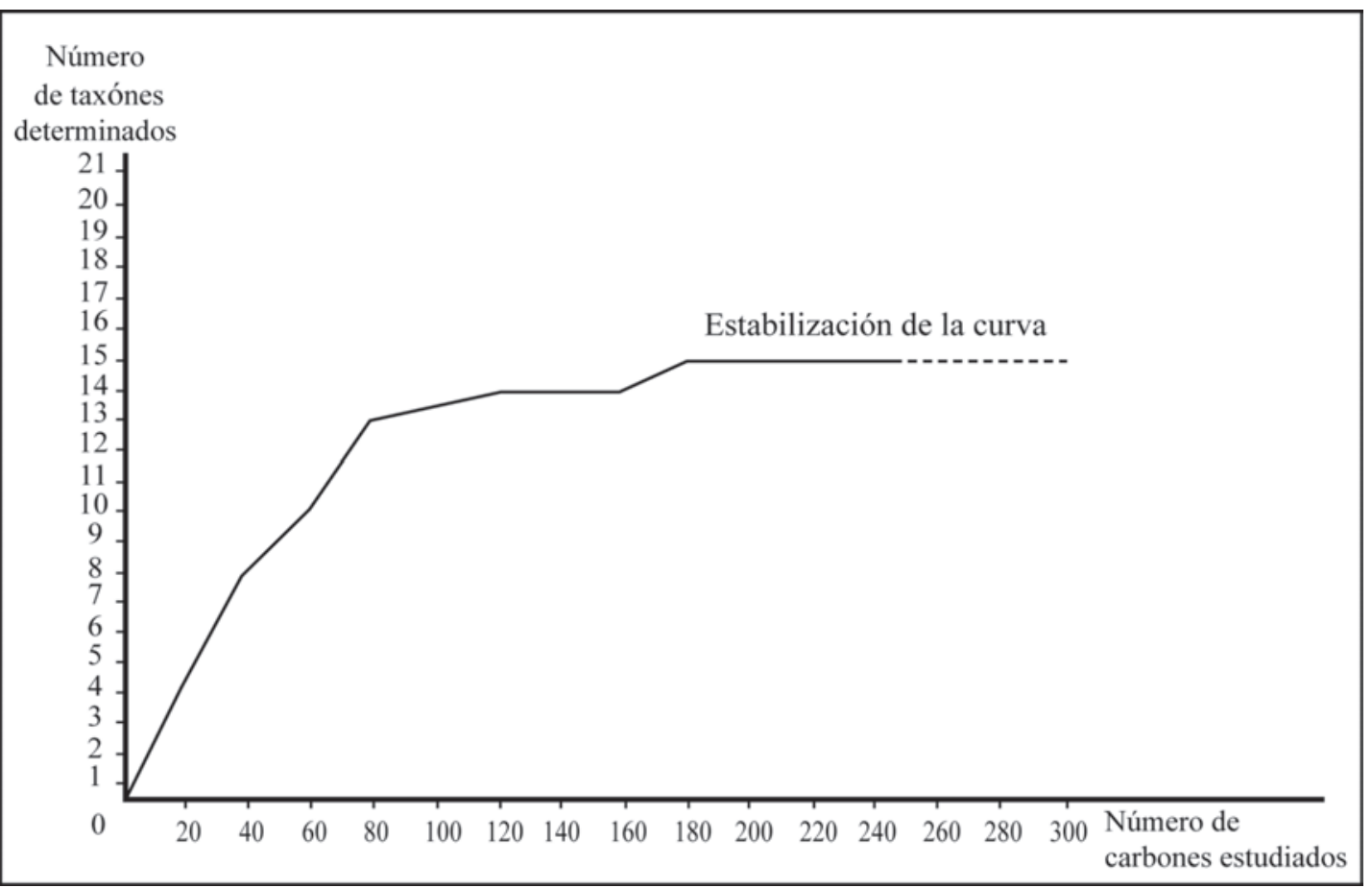

Figura 4. Curva esfuerzo / rendimiento.

Presentación de los resultados

Los resultados de un estudio antracológico se presentan bajo la forma de un diagrama (Fig. 5), en el cual figuran por cada contexto el porcentaje de cada taxón; lo que se llama un espectro antracológico. El contexto más antiguo aparece en la parte baja del diagrama y el más reciente en su parte alta, lo cual permite observar las evoluciones o continuidades del espectro antracológico. En general, se agrupan las especies que tienen afinidades ecológicas para aislar los tipos de asociaciones vegetales.

Según el nivel de determinación al cual se pudo llegar, aparecen nombres de familias, géneros o especies. Se presentan también los indeterminados, es decir, especímenes que no fueron determinados hasta el momento por falta de material de referencia o mala conservación. En general, se encuentran también en las muestras especímenes calificados como indeterminables. Suele tratarse, o de carbones tan deformados (por la vitrificación, por ejemplo) que nunca podrán ser determinados o, de carbones en los cuales no aparecen criterios diagnósticos. Esta categoría no está incluida en los cálculos estadísticos pues no se puede sacar información de ella.

\section{Interpretación de los resultados de los análisis antracológicos \\ Adquisición de datos en las ciencias naturales, humanas y sociales}

El diagrama antracológico es la base a partir de la cual se empieza la interpretación de los resultados. Con la ayuda de datos externos, se trata de aislar, en el diagrama, asociaciones vegetales características (bosque seco, monte ribereño) o patrones de comportamientos humanos reconocibles (de recojo, de actividad).

\section{Las ciencias naturales}

Un carbón resulta de la carbonización de una madera que proviene de un árbol, el cual es 


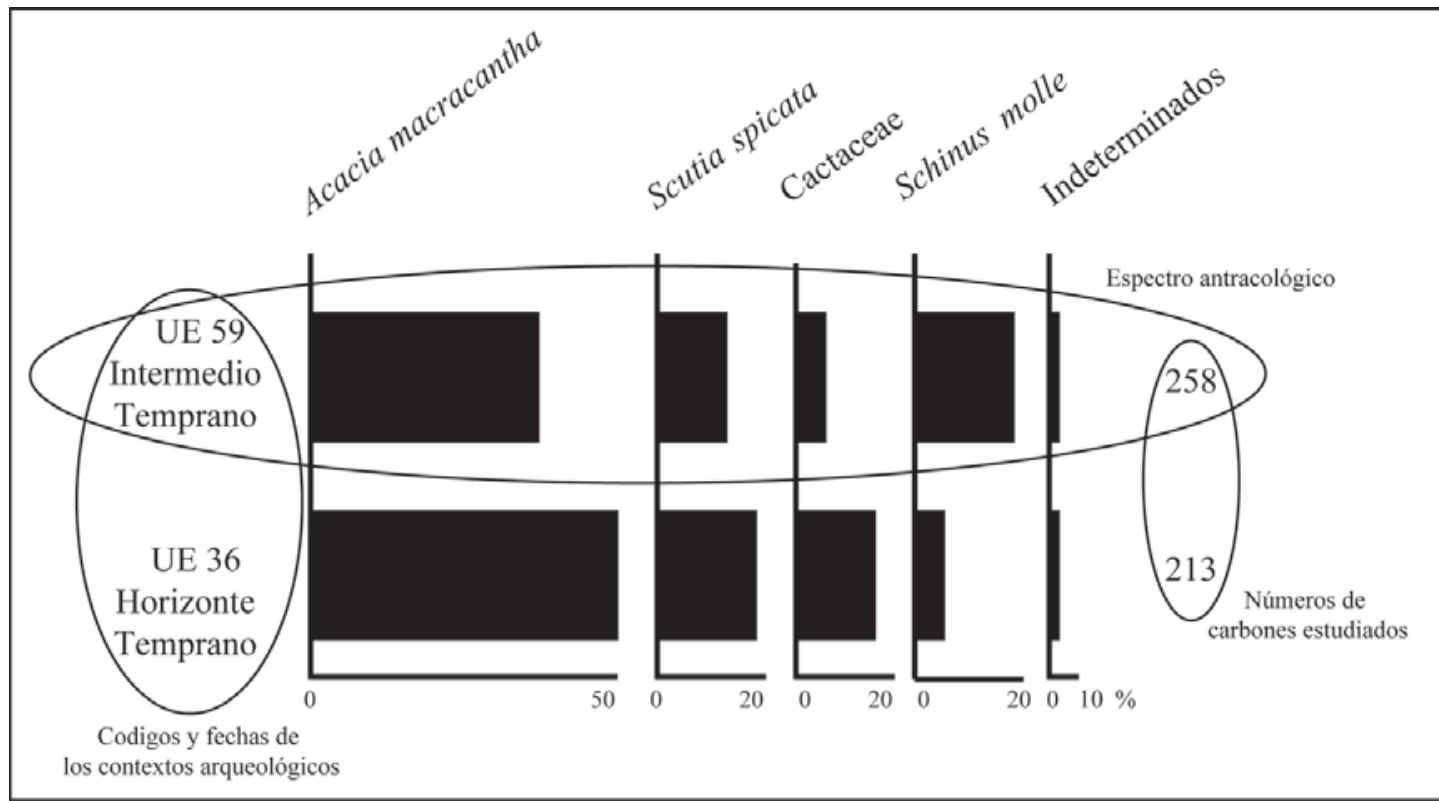

Figura 5. Modo de empleo de un diagrama antracológico.

parte de un ambiente que se define por un suelo, un clima y una topografía. Conocimientos básicos en botánica y ecología son indispensables para entender e interpretar los datos antracológicos.

En antracología, se atribuye a determinadas especies leñosas exigencias ecológicas parecidas a las de sus homólogos actuales. Son agrupadas en asociaciones vegetales, según las afinidades reconocidas por la fitosociología ${ }^{4}$ (Fig.6). Ciertas asociaciones son características de un piso bioclimático (la puna, la yunga). Los diferentes pisos forman un escalonamiento de la vegetación que depende sobretodo de la temperatura y sigue un gradiente altitudinal y longitudinal. El orden de sucesión de estos pisos es constante, pero sus límites superiores e inferiores pueden variar bajo la influencia de factores climáticos y/o antrópicos. Otras asociaciones son vinculadas a ambientes particulares naturales (monte ribereño, borde de mar) o condicionados por el hombre (huertas, andenes) (Delhon et al. 2003). Es necesario conocer la ubicación de las especies leñosas en el paisaje actual y sus exigencias ecológicas para poder identificar los lugares de abastecimiento de leña o madera de las sociedades pasadas, proponer reconstituciones paleoambientales o poner de manifiesto evoluciones climáticas.

\section{Las ciencias humanas y sociales}

Detrás de cada trozo de madera que se encuentra en un sitio arqueológico está la mano del hombre que lo ha cortado o colectado, utili-

${ }^{4}$ La fitosociología es el estudio de las tendencias naturales, manifestadas por poblaciones de especies diferentes, a cohabitar en una comunidad vegetal o a excluirse según sus exigencias ecológicas (climáticas, edáficas, bióticas). Las comunidades reúnen un conjunto de especies, dominantes y dominadas, que las definen. Por ejemplo, el monte ribereño es una comunidad vegetal que, siendo instalada en los bordes de un río, aprovecha del agua todo el año y tiene un suelo rico en aluviones. está dominado por el sauce (Salix chilensis), el pájaro bobo (Tessaria integrifolia) y la caña brava (Gynerium sagittatum), especies que necesitan mucha agua y suelo rico en materia orgánica para crecer, pues no pueden vivir en otro tipo de ambiente. 
zado y finalmente desechado. Las ciencias sociales ayudan a descifrar los comportamientos de los hombres y sociedades del pasado. Datos etnológicos, etnohistóricos y etnobotánicos, que tienen una cierta homogeneidad de espacio, tiempo y cultura, con los datos arqueológicos estudiados, contribuyen a acercarse al pasado con un enfoque regresivo desde el presente. Por supuesto, la ponderación es de rigor. Estamos hablando de medios que ayudan a entrever ciertas realidades del pasado difíciles de alcanzar, tales como las creencias, la organización social, los mitos, etc.

Raros son los textos etnohistóricos que mencionan bosques, madera utilizada como materia prima o leña, gestión de los recursos vegetales o plantas cultivadas. Sin embargo, los relatos de la conquista, los relatos de viajes y las extirpaciones de idolatría representan una fuente interesante de infor-

Figura 6. Ejemplos de asociaciones vegetales: 1) Monte ribereño, valle medio de Lurín,

Lima; 2) Lomas de Pueblo Viejo-Púcara,

Lima; 3) Huerta, Simbal, La Libertad.
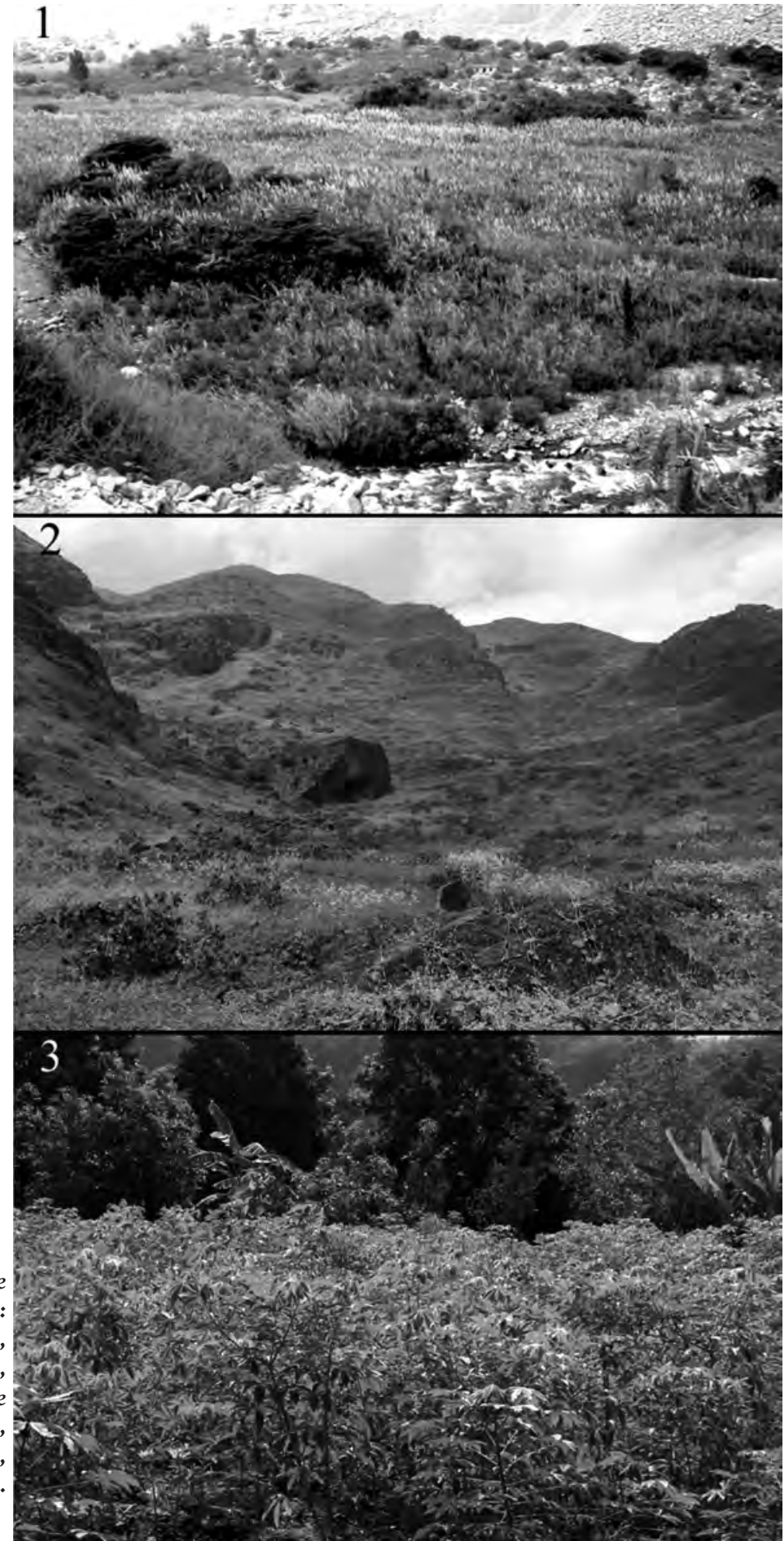
Figura 7. "Segunda calle - puric macho" (viejo que camina). Los mayores pasados de edad de sesenta años y de setenta y ocho años servían para traer leña (sacado de Guaman Poma de Ayala 1987[1615]: 191).

mación (Fig.7), (Santacruz Pachacuti 1968[1613] ; Guaman Poma 1987[1615] ;Cobo 1964[1653]).

Siempre hay que tener presente que el paisaje en los Andes no era visto por los antiguos peruanos sólo como un paisaje geográfico, sino también como un paisaje sagrado. Los elementos resaltantes del paisaje son a menudo Huacas. En la zona de Huarochirí (departamento de Lima) conocida gracias al manuscrito epónimo (Taylor 1980), la distribución de los asentamientos humanos refleja los linajes de las divinidades principales de la zona. El árbol es parte del paisaje, y algunas especies como el lloque (Kageneckia lanceolata) o la lúcuma (Pouteria lucuma), son sagradas (Taylor 1980).

Sabemos por la etnología que los árboles son a veces considerados como ancestros (Ansión 1986). El cronista indígena Juan Santacruz Pachacuti (1968[1613]) menciona que las madres y los padres de los Incas eran árboles. En la terminología quechua, la palabra mallki sirve para designar tanto a los ancestros como a los árboles. El paralelo entre árboles y ancestros se vuelve a encontrar en la imagen, según la cual, los abuelos son las raíces de la familia y producen frutos los hijos (Sherbondy 1988).

Todo eso pudo haber influido en las colectas de madera o leña. La ausencia de especies consi-

deradas como sagradas en un corpus antracológico no necesariamente significa que no existían en el ambiente pasado, sino que tal vez no eran recogidas por causa de prohibiciones, por ejemplo. Es un elemento a tomar en cuenta al momento de la interpretación de los resultados.

D. Walter, que trabajó en el Parque Nacional Huascarán (departamento de Áncash), refuerza esta idea comentando sobre una especie que los campesinos de esta región no tienen derecho a cortar como leña: el hupay chukru (Monnina salicifolia). Según los mitos locales, si esta leña se utiliza para cocinar, la olla revienta, provocando 
escasez de víveres e incitando a los hombres a comerse entre ellos, como en los tiempos míticos (Walter 2002). ¿Cómo se podría encontrar en el material arqueológico restos de una planta cuya utilización significa desastres para toda una comunidad?

En el Perú se encuentran zonas donde la gente sigue viviendo de manera muy tradicional y dependiendo de los recursos naturales para su vida cotidiana. La búsqueda de agua y de leña, indispensables para cocinar y calentar, ocupa una parte importante de las actividades diarias (Fig.8). El conocimiento de tales sociedades contemporáneas nos brinda un juego de ideas para pensar a través de las evidencias arqueológicas, como herramienta de trabajo.

\section{Problemáticas de estudio \\ Las problemáticas tocadas por el estudio de maderas y car- bones se dan en función del contexto del cual fueron extraídas las muestras. Pero la problemática general de un estudio antracológico es el conocimiento de las relaciones entre el hombre y el ambiente en el cual vivió.}

Reconstitución paleoambiental e interpretación paleo-ecológica

Las estratigrafías naturales

Las estratigrafías naturales son zonas de acumulación

Figura 8. Colecta y utilización doméstica de la leña en la región de Huarochirí. natural de sedimentos (lecho de río, vertientes) donde se encuentran a veces capas de carbones que se integraron a las capas superficiales o más profundas del suelo como producto de incendios, producto de fuegos espontáneos o debido a la acción antrópica.

Varios estudios ya demostraron que desde el Mesozoico existen tanto fuegos naturales favorecidos por razones ecológicas, como periodos largos de sequía. Son fenómenos cíclicos controlados por dinámicas climáticas independientes de las actividades humanas. No se trata de una degradación irreversible de las comunidades florísticas indígenas, pero si de una regulación eco-

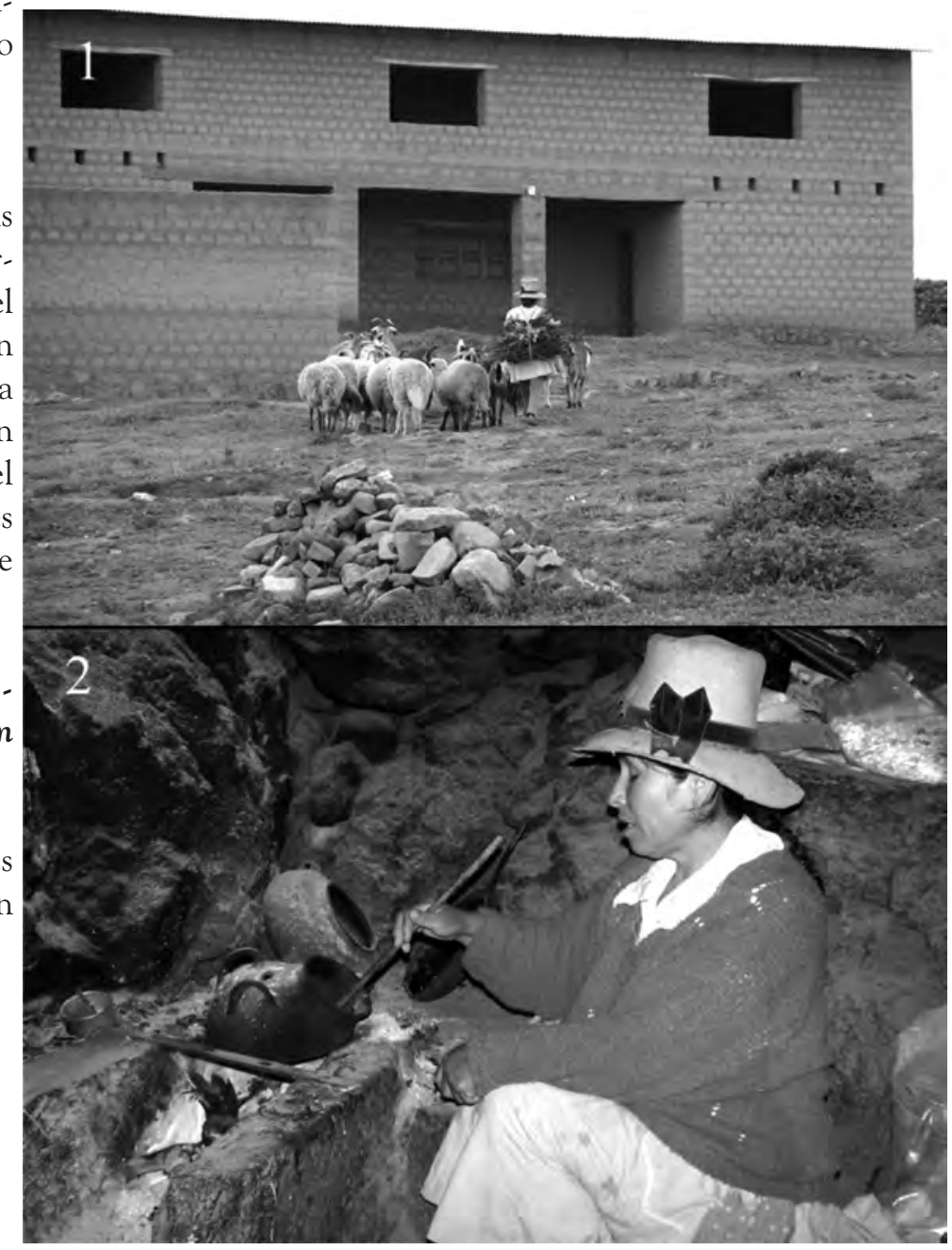


lógica de la vegetación. Después de un tiempo, se restablece una relativa estabilidad ecológica y florística. Estos incendios permiten a la vegetación regenerarse (Berger \& Thiébault 2002). En el lago Titicaca se descubrieron niveles de paleoincendios fechados entre 17700 a 13500 aP., es decir, antes de la llegada del hombre en la zona (Paduano 2003).

También el hombre utilizó y sigue usando el incendio a gran escala. El fuego es empleado como técnica de caza para ojear los animales de los bosques. En las sociedades que practican la agricultura, los incendios sirven para abrir o limpiar nuevos espacios de cultivo, desbrozar o fertilizar la tierra. Es el caso de la agricultura sobre chamicera en varias regiones del mundo o de las terras pretas en la selva amazónica (Woods 2000).

Sean naturales o antrópicos, estos niveles de carbones tienen una gran ventaja, pues dan la imagen de una comunidad vegetal leñosa en un momento, donde no interviene una selección humana de especies, es decir, sin filtro humano de recojo. Si, además, en una misma estratigrafía se encuentran varios niveles de incendio, existe una profundidad cronológica que permite observar las variaciones de la vegetación y del clima o de la explotación del ambiente por el hombre.

Los carbones dispersos y la representatividad paleoecológica (Fig. 9)

Los carbones dispersos provienen de un gran número de fuegos, esparcidos durante la formación de las capas arqueológicas, que pueden ser de varios años o décadas. Tomando como presunción que un hombre se queda por un largo tiempo en la misma área y recorre todo el territorio que rodea su lugar de vivienda y/o de actividad en busca de leña, se propone un diagrama antracológico, obtenido con carbones dispersos en capas de larga ocupación doméstica, que refleja la vegetación pasada de los alrededores del sitio estudiado. En contraste, los carbones concentrados (fogones o acumulaciones) refle- jan una duración de actividad corta, por lo tanto, una explotación parcial del territorio (Chabal 1997). También en la óptica de reconstitución del ambiente pasado, son más interesantes los carbones procedentes de fuegos domésticos y no de actividades especializadas (hornos para cocer cerámica o metales, por ejemplo), porque se supone que no hay una selección de especies, sino que la leña fue colectada de manera oportunista según la disponibilidad (Vernet 1973, Chabal et al. 1999, Zapata-Peña et al. 2003) y así refleja la vegetación próxima. En estos casos, la antracología propone que el espectro de frecuencias, obtenidas por el estudio de carbones, transmite, bajo una forma transformada y sintética, una representación de la vegetación leñosa de la zona de abastecimiento de leña para fuegos domésticos, en un intervalo de tiempo dado (Chabal 1992). La reproducibilidad de los análisis al interior de una misma capa, entre muestras de diferentes capas, pero de una misma época, y entre muestras de diferentes sitios de misma época, asegura la validez y la representatividad paleo-ecológica.

A partir del momento en que esta representatividad queda demostrada, el estudio del material procedente de estos dos tipos de contextos (estratigrafías naturales, carbones dispersos en capas de ocupación doméstica) permite, mediante el estudio de las variaciones o permanencias de conjuntos vegetales diacrónicos, entender la evolución del paleo-paisaje vegetal y del paleo-clima. No se razona sobre el porcentaje de una especie, sino sobre las proporciones entre las diferentes especies. Si estas proporciones reflejan, en un nivel, una vegetación asociada a un piso ecológico de piemontes y luego, en un nivel ulterior, se incrementan por ejemplo los porcentajes de especies de más altura, se postula que el clima se ha enfriado. Lo mismo que si especies asociadas a un clima seco, en un primer tiempo mayoritarias, se ven reemplazadas en un segundo tiempo, por especies características de un clima 


\section{La interpretación palco-ecológica}

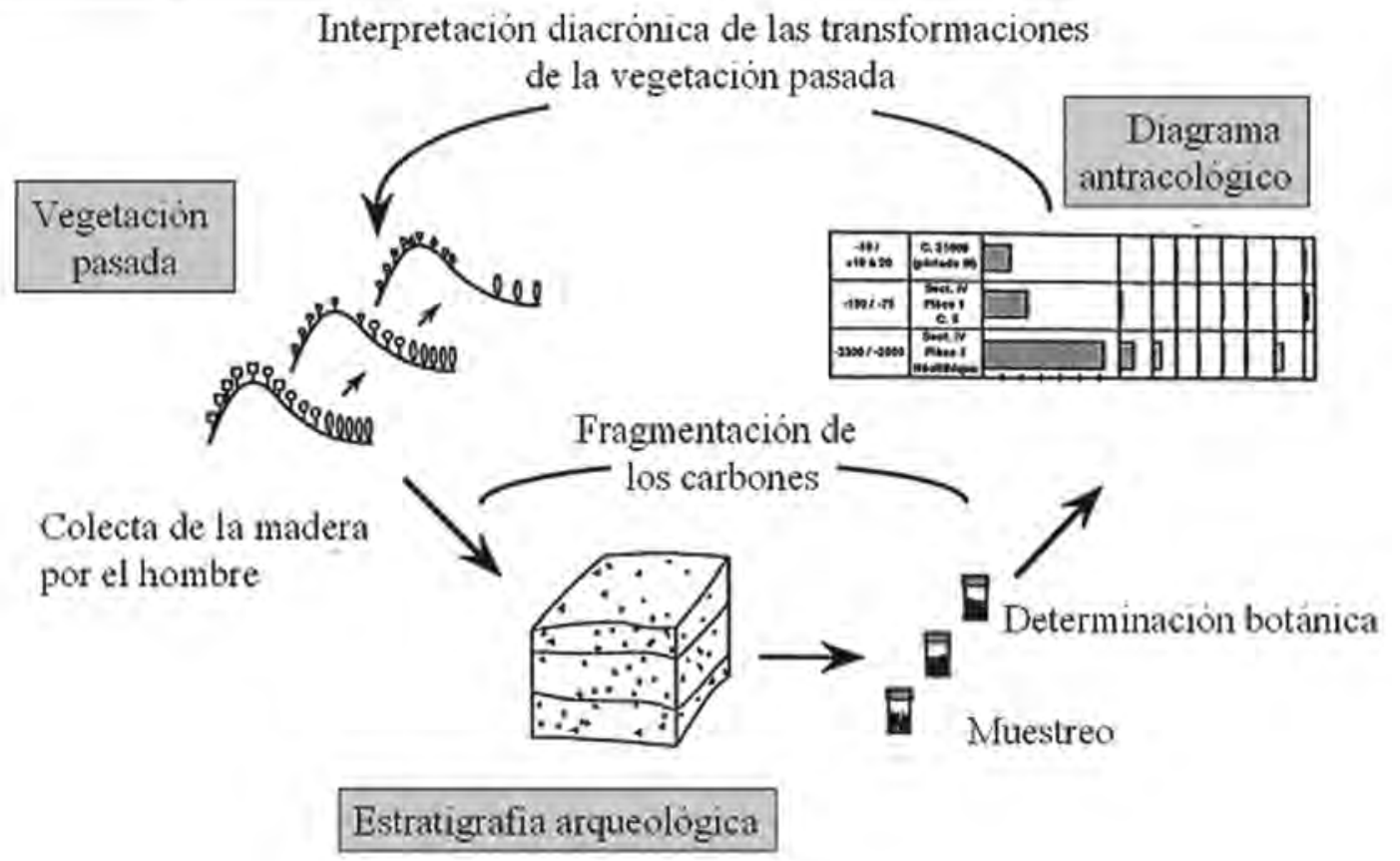

Figura 9. Esquema explicativo de la representatividad paleo-ecológica (según Chabal 1992).

húmedo, se propone que hubo un cambio en el régimen de lluvias.

Si los datos no son suficientes para llegar a una reconstitución paleo-ambiental, queda la posibilidad, mediante los espectros antracólogicos obtenidos, de determinar cuales fueron las zonas ecológicas explotadas por el hombre para recoger leña, a través del conocimiento de la ecología actual de las plantas. Saliendo de las localizaciones actuales de las asociaciones vegetales identificadas, de las coacciones topográficas, hidrográficas, geológicas y edáficas a las cuales son sometidas, se propone ubicarlas en el espacio, lo que permite dar una idea del site catchment", es decir, del espacio de captación de recursos de un sitio.
Se estudió un corpus de 636 carbones procedentes de la pyramide III de Pachacamac (Moutarde 2006). La pyramide III con rampa de Pachacamac fue ocupada durante el Intermedio Tardío y luego reocupada como cementerio durante el Horizonte Tardío y la época colonial (Eeckhout y Farfan 1999). El material estudiado proviene de la plaza $\mathrm{V}$ y del patio 25 que eran espacios dedicados a la preparación de los alimentos destinados a la elite que vivía en este conjunto. También se criában cuyes y se fabricaban textiles in situ. Los carbones eran dispersos en dos niveles fechados del Período Intermedio Tardío 7 (1410-1440 d.c.) y del Período Intermedio Tardío 8 (1440-1476 d.c.) que corresponden a la fundación y ocupación de 
estos espacios - para el primer nivel - y al abandono de la estructura - para el segundo nivel. Se presenta en la figura 10 el diagrama antracológico obtenido a partir del estudio de este material, por fase. Los dos espectros antracológicos de la plaza $\mathrm{V}$ y del patio 25 se encuentran dominados por los Prosopis/Acacia/Caesalpinia/Inga (algarrobo, huarango, tara, pacae) $-51,5 \%$ para la fase de ocupación y 50,7\% para la fase de abandono - y luego por Fabacaeae (13,9 y 8,8\%), Pouteria lucuma (lúcumo - 7,8 y 8,5\%) y Baccharis sp. (Chilco - 10,2 y 5\%). Los Asteraceae, Cactaceae, Salix sp. (sauce), Tessaria integrifolia (pájaro bobo), Psidium guajava (guayabo), Manihot esculenta (yuka), Alnus acuminata (aliso), Amaranthaceae / Chenopodiaceae y cf. Calceolaria sp. están presentes pero en proporciones inferiores a $5 \%$.

El sauce, el pájaro bobo, el chilco y el aliso son especies estrictamente de borde de río. El lúcumo, el guayabo y la yuka son especies cultivadas. Los Asteraceae, Cactaceae, Amaranthaceae/Chenopodiaceae y cf. Calceolaria sp. son taxa ubiquistas. Al nivel anatómico, la madera de los géneros Prosopis, Acacia, Caesalpinia y Inga, de la familia Fabaceae, es muy parecida, por lo cual a veces no se pueden distinguir los unos de los otros. Para mayor comodidad, se reunieron en una sola categoría los carbones de estos 4 géneros, pero la mayoría de los especimenes eran de algarrobo o de huarango.

Los resultados obtenidos con el estudio de los carbones de la Pyramide III de Pachacamac demuestran que la leña que usaban en este lugar, durante el Período Intermedio Tardío, provenía de árboles que crecen en el monte ribereño o de especies cultivadas. Lo más probable es que estas taxa se encontraban en la desembocadura del Lurín, como en la actualidad, porque las especies de monte ribereño, como el pájaro bobo o el chilco, no pueden vivir lejos de un río y porque las tierras agrícolas más ricas, donde se supone que crecían los lúcumos, guyabos y yukas, han estado antes, como hoy día, en el lecho del río. Este análisis suele precisar que la composición florística del monte ribereño no ha cambiado del Período Intermedio Tardío hasta el presente y que se cultivaba en la zona lúcumos, guayabos y yukas. Acerca de los algarrobos y huarangos, el asunto no es tan claro.

En la actualidad, el algarrobo casi ha desaparecido de la costa central. Es la especie más abundante en la formación vegetal conocida como bosque seco o algarrobal ${ }^{5}$, que se encuentra en la costa norte del Perú y en la región de Ica. En cuanto al huarango, es una especie que se cruza tanto en los bosques secos como en el monte ribereño, en la costa y hasta 3500 m.s.n.m. Hoy en día existen algunas manchas de huarangos en el valle bajo de Lurín. El fuerte porcentaje de algarrobos y huarangos en el material antracológico de Pachacamac y el hecho de que esta dominancia se repite en los dos niveles habla en favor de la presencia de grandes poblaciones de estas dos especies en la cercanía del sitio, lo que no ocurre hoy en día.

Los textos etno-históricos, como la descripción de Pachacamac al momento de la llegada de Hernando Pizarro en 1533 por F. De Jerez (1968[1534]), mencionan la existencia de bosques densos en la costa en los alrededores del santuario. Por las características ecológicas de estas dos especies y por el hecho de que las tierras más ricas de la zona, es decir las que estan en la desembocadura del río, eran dedicadas a la agricultura, se propone que existía, en el Período Intermedio Tardío, una formación vegetal tipo bosque seco, en el llano costeño al norte y al sur de Pachacamac, fuera de las tierras agrícolas. Los

5 El algarrobo es una planta freatofítica es decir que se caracteriza por un sistema radicular muy desarrolado que le permite buscar agua en las napas freáticas, a una gran profundidad. 


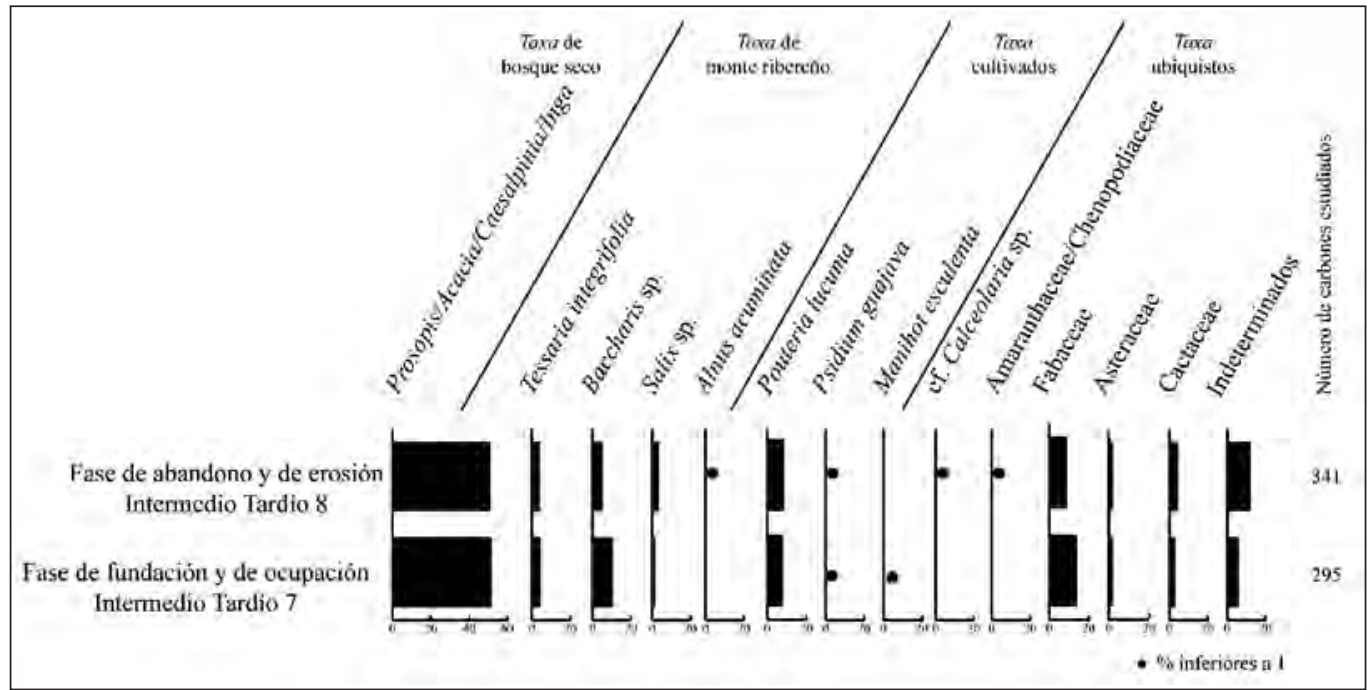

Figura 10. Diagrama antracológico de la Plaza V y del patio 25 de la Piramide III de Pachacamac. Resultados en \%, sobre un total de 636 carbones.

resultados de otros estudios antracológicos que se realizarón sobre material de Pachacamac, procedente de niveles fechados de los períodos Intermedio Temprano y Horizonte Tardío (Moutarde 2006), dieron a conocer que este supuesto bosque estaba presente desde el Período Intermedio Temprano y que se mantuvo hasta la conquista, a pesar de una fuerte presión antrópica originada por un crecimiento demográfico importante en el valle de Lurín del Período Intermedio Tardío al Período Horizonte Tardío.

\section{La economía de los combustibles y de la madera}

El estudio antracológico permite también tratar temas como los usos de la madera en el pasado relacionados a las actividades humanas, las tecnologías y la economía vegetal. Hasta el momento, como casi no hubo estudios antracológicos sobre el Perú prehispánico, no se pueden presentar datos detallados sino sólo proponer pistas de investigación.

\section{Eluso de la madera}

Estudiando el material extraído de fogones o de concentraciones de carbón, se puede apreciar si los antiguos peruanos utilizaban como combustible sólo madera o también cañas, coprolitos, etc. El análisis de fogones de función diferente (doméstica, artesanal, ritual), diacrónicos, permite ver si había una selección de las especies según las actividades y si varió con el tiempo.

Los sistemas técnicos se abordan gracias al estudio de los artefactos (elementos de construcción, herramientas). En este caso, el interés es estudiar mucho material para ver si se destacan utilizaciones precisas de algunas especies según las actividades, las épocas y los lugares, poniendo en relieve las cualidades físicas de la madera (dureza, incorruptibilidad). En cuanto a las huellas observadas en las maderas, dan información sobre las herramientas utilizadas y, por lo tanto, de técnicas utilizadas para cortar la madera o tallarla.

\section{Lagestión de los recursos}

La gestión del recurso leñoso es otro tema que se puede abordar con el estudio del material antracológico. El árbol vivo, tal como la madera, forma parte de un sistema productivo. En los Andes el árbol más escaso del paisaje sirve para 
varios propósitos dentro del ambiente de vida y de trabajo de la gente, como por ejemplo, para dar sombra, para decoración, para forraje de los animales, para combatir la erosión del suelo o para albergar a los animales silvestres (Reynel \& Felipe-Morales 1987). En algunos casos, es usado directamente en el sistema agrícola para proteger los cultivos de un sol demasiado fuerte, limitar la evapo-transpiración o, en el caso de las Fabaceae (pacae, tara), para enriquecer el suelo en azote. Se trata de prácticas agro-forestales, es decir, de formas de usar los árboles para mejorar la productividad agrícola. La presencia, en el material antracológico, de especies no coherentes con un tipo de medio o la sobrerepresentación de taxones normalmente escasos, puede atestiguar tales prácticas.

Otro aspecto del manejo de los recursos leñosos es la gestión de los bosques o asociaciones vegetales espontáneas como fuente de abastecimiento de madera o de leña. Existe una necesidad en los grupos humanos de conseguir madera como materia prima o combustible. Con un cuidado razonable, en el caso de pequeñas sociedades, se las puede manejarlas con poco impacto sobre el ambiente. En cambio, el crecimiento demográfico multiplica la demanda de estos productos y ejerce una presión importante en el medio que puede traducirse en una talla más importante de árboles y arbustos. Si en una misma zona el registro antracológico es estable en el tiempo, a pesar de un fuerte aumento de la población, se puede trabajar sobre la hipótesis que hubo una política de gestión de los recursos de parte de autoridades y tratar de determinar de qué tipo era. Por el contrario, si se nota un cambio en los espectros antracológicos, se puede evaluar cuál fue el impacto de la presión demográfica y del aumento de la demanda en leña y madera sobre la cobertura vegetal.

Para poner en evidencia las prácticas agroforestales o las estrategias de gestión de los bosques de las sociedades pasadas, y para impedir interpretaciones erróneas de los resultados, es preciso cruzar los datos antracológicos con los de otras disciplinas paleo-ambientales como la palinología (estudio de granos de polen y de esporas fósiles), la carpología (estudio de frutos y semillas encontrados en contextos arqueológicos) o la arqueozoología (estudio de restos óseos animales encontrados en contextos arqueológicos). Por ejemplo, la presencia de vainas de algarrobo (Prosopis spp.), en un nivel arqueológico en el cual no hay carbones de algarrobo, hablará en favor de una explotación de esta especie por sus frutos y no de su inexistencia en el ambiente. La presencia de huesos de animales silvestres en niveles arqueológicos en los cuales sólo aparecen carbones de cañas nos orientará hacia una explotación de un bosque como reserva de caza y no hacia un ambiente que carece de bosques. También los datos etnohistóricos y etnológicos pueden ayudar a entender mejor la gestión de los recursos naturales del pasado. Algunos textos etnohistóricos mencionan medidas tomadas por los Incas para limitar la sobre-explotación de los recursos leñosos. Guaman Poma (1987[1615]), por ejemplo, cita una prohibición de cortar frutales, madera o paja sin licencia, so pena de muerte y castigos.

\section{Los intercambios}

Los intercambios se pueden apreciar por la presencia de especies raras o no originarias de la región. Se encontrará, en general, en contextos particulares de tipos litúrgicos, funerarios o en el marco de actividades especiales vinculadas con la producción de artefactos. Muestras aisladas dan indicios, pero tienen que ser relacionadas con otros datos.

\section{Elmundo ritual}

El mundo ritual del pasado es una de los aspectos más difíciles de estudiar en arqueología porque deja pocos testigos materiales. En el Perú antiguo, según los textos etnohistóricos (Gua- 
mán Poma de Ayala 1987[1613]), las ofrendas hacia las divinidades o las Huacas eran a veces quemadas (Fig.11). Los carbones encontrados en un contexto claramente definido como ritual, en particular en estructuras de combustión donde se supone que hacían las quemas rituales, darían a conocer si había una selección de especies para los rituales (si habían pocas especies y
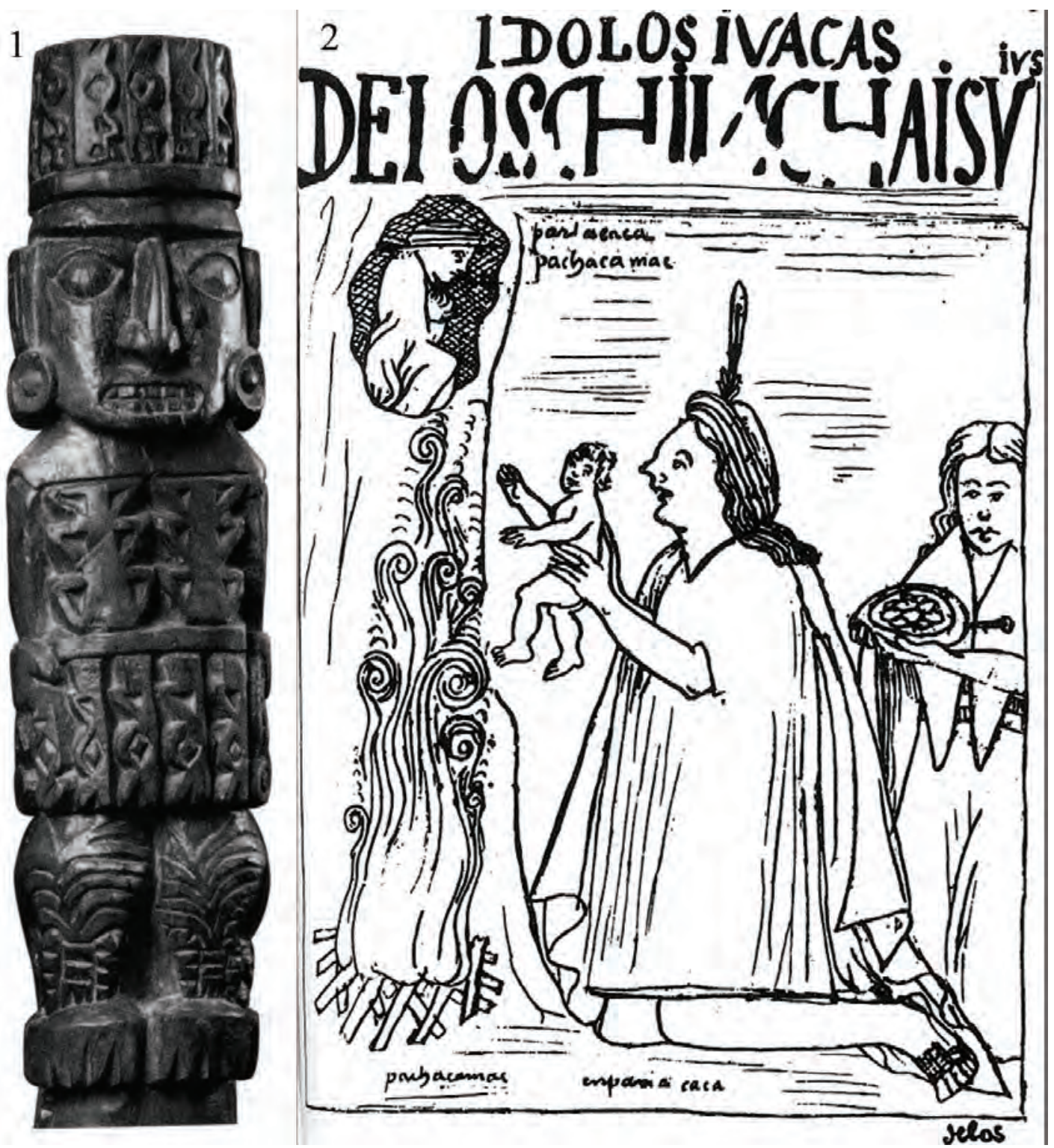

Figura 11. El mundo ritual de los antiguos peruanos. 1) El "Ídolo" de Pachacamac (según Rostworowski 2002: 44) ; 2) "Idolos y vacas de los Chinchai svivs".

Sacrificio humano ritual en presencia de un fuego (sacado de Guaman Poma de Ayala 1987[1615]:259). 
siempre las mismas) y si esta selección se puede vincular con datos existentes sobre el valor simbólico de algunas especies ("lúcuma", "lloque", "quishuar", etc). Igual sería para los carbones encontrados en tumbas, que son también contextos rituales, pero más vinculados con los rituales funerarios y el culto a los ancestros.

Hemos estudiado tres postes de madera esculpidos, conservados en el Museo Quai Branly (Paris, Francia) bajo los números de inventario 71-1911-21-503, 504 y 506 (Fig.12). Fueron comprados en 1911 en Lima, por el Capitán Berthon, como "ídolos procedentes del cementerio de Pachacamac" y regalados al museo de etnografía de Paris, actualmente el Museo del Hombre. Al momento de entrar en las colecciones del museo, la autenticidad de estas tres piezas fue puesta en duda, pero una comisión de expertos estimó que eran antiguas (1911). Se sacaron muestras de cada uno de estos postes con hojas de afeitar, aprovechando de las fisuras de las maderas. Se practicaron cortes en las muestras hasta obtener cortes transversales satisfactorios que permitieron determinar que los tres postes eran hechos de lúcumo (Pouteria lucuma ) (Moutarde 2006). Si bien esto no confirma la antigüedad de las piezas, este análisis certifica que fueron hechas con madera local, lo que quita una parte de la duda sobre su autenticidad.

Se considera generalmente que los postes y vigas que se encuentran en contextos arqueológicos en la costa peruana son de algarrobo (Prosopis sp.), por la dureza y la inalterabilidad de esta madera y su abundancia en el paisaje. Sin embargo, parece que la madera del lúcumo también se usó bastante para la construcción y la escultura. Además de estos postes esculpidos, de los pocos artefactos de madera que fueron determinados para la época precolombina en el Perú, se ha registrado que la escultura conocida como el Ídolo de Pachacamac (Fig.11) es hecha de lúcumo (Dulanto 2001). De la misma forma, un poste esculpido de la época mochica, encontra-

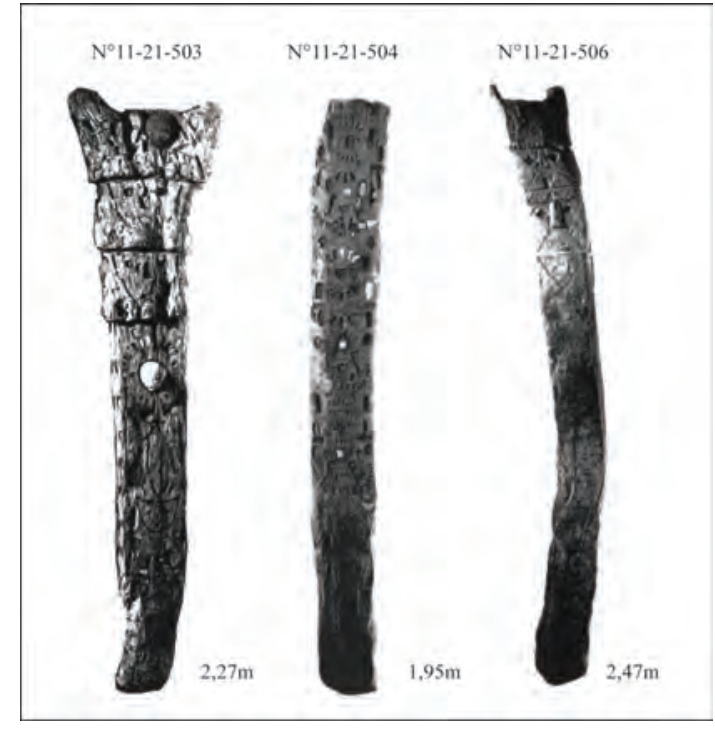

Figura 12. 1) Postes esculpidos de madera procedentes de Pachacamac (según Fauvet-Berthelot y Lavallée 1988) ; 2) corte transversal $x$ del poste $N^{\circ} 11-21-503$ - Pouteria lucuma.

do en la Huaca Cao Viejo - valle de Chicama fue hecho con madera de lúcumo (Franco et al. 2001).

La madera de lúcumo, a parte de ser dura y resistente, tiene un grano muy fino y un color marrón-anaranjado, lo que le da a la vez propiedades físicas interesantes para la construcción o la escultura y un valor estético. También se reconoce en el manuscrito de Huarochirí, que tenía un valor simbólico (Taylor 1980). Solo la multiplicación de determinaciones de artefactos de madera precolombinos brindará elementos para aclarar si había una selección de la madera de lúcumo para la construcción o la fabricación de esculturas, según sus propiedades físicas o su valor simbólico.

\section{Conclusiones}

De la presentación de los métodos de recojo y de análisis del material antracológico, así como de los mecanismos de interpretación de los resultados que se han expuesto en este artículo, resaltan algunas observaciones: 
1- El estudio de maderas o de carbones arqueológicos en la arqueología peruana es aún incipiente. Por lo tanto, considero que con un material de referencia eficaz, esquemas interpretativos adaptados a la realidad andina y la multiplicación de los análisis antracológicos, se puede desarrollar rápidamente.

2 - El diálogo entre los arqueólogos y los antracólogos es la piedra angular para realizar un análisis antracológico eficiente. En efecto, el potencial informativo del material depende del contexto en el cual fue encontrado y de la manera como fue colectado. Es indispensable definir una estrategia de recojo de las muestras durante las excavaciones, según una problemática definida anteriormente.

3 - Si bien la antracología se basa en la determinación taxonómica de las muestras de carbón, ésta tiene un enfoque interdisciplinario en la etapa de la interpretación de los resultados que le permite ir más allá de meras constataciones de presencia/ausencia. El aporte de las ciencias naturales, humanas y sociales amplía la dimensión al estudio antracológico.

4 Los estudios antracológicos permiten tratar temas como la evolución del paisaje y la gestión de los recursos vegetales en los tiempos prehispánicos. También dan acceso a informaciones sobre el uso de la madera, los intercambios y el mundo ritual.

Hasta ahora, la arqueología andina, y peruana en particular, se ha fijado mayormente en las cuestiones de cronología o de atribución cultural. Un nuevo desafío para ella es la comprensión del ambiente en el cual vivían las sociedades precolombinas, particularmente para entender las elecciones de implantación de los sitios y, más allá, los esquemas de explotación de los recursos naturales y la territorialidad de dichas sociedades. Las disciplinas paleo-ambientales, y entre ellas la antracología, tienen en este punto un papel importante que jugar, volviendo a colocar al hombre del pasado en su ambiente vegetal. La temática de las interacciones hombre/ambiente, sobre todo de la gestión de los recursos, no sólo interesa a la arqueología, también se encuentra en el centro de las preocupaciones del mundo actual. En una perspectiva de desarrollo sostenible, conocer los modos de manejo que funcionaban en el pasado puede ayudar a tomar medidas para la explotación duradera o la conservación de ecosistemas sobre explotados o degradados en la actualidad.

\section{Agradecimientos :}

Queremos agradecer a Peter Eeckhout (Université Libre de Bruxelles) quien nos confió el estudio del material antracológico de la Piramide III de Pachacamac y a Víctor Paredes y Rafael Vega-Centeno, quienes nos ayudaron con la corrección linguística de este texto.

\section{Bibliografía}

Ansion, Juan

1986 El árbol y el bosque en la sociedad andina. Lima,Proyecto FAO-Holanda/INFOR.

Berger, Jean François \& Thiebault, Stéphanie

2002 "The study and significance of charcoal as an indicator of ancient fires : an application to the middle Rhone valley (France)". En Charcoal Analysis. Methodological Approaches, Palaeoecological Results and Wood Uses. Proceedings of the Second International Meeting of Anthracology, Paris, September 2000, S. Thiebault (ed.). BAR International Series 1063, pp.25-41. Oxford, England.

Boulard, Bernard

1988 Dictionnaire de botanique. Paris: Ellipses. Brako, Lois \& Zarucchi, James, L.

1996 Catalogue of the flowering plants and gymnosperms of Peru. Monographs in Systematic botany from the Missouri Botanical Garden, 45. St Louis : Missouri Botanical Garden. 
Chabal, Lucie

1992 "La représentativité paléo-écologique des charbons de bois archéologiques issus du bois de feu". Bulletin de la Société Botanique de France, Actual. bot., 139 $(2 / 3 / 4): 213-236$.

1997 Forêts et Sociétés en Languedoc (Néolithique final, Antiquité tardive) L'anthracologie, méthode et paléoécologie. DAF N ${ }^{\circ} 63$. Paris : Editions de la maison des sciences de l'homme.

Chabal, Lucie, Fabre, Laurent, Terral, Jean F. \& Thery-parisot, Isabelle

1999 «L'anthracologie ». En La Botanique, C. Bourquin-Mignot et al., pp. 43-104. Collection "Archéologiques". Paris : Editions Errance.

Cobo, Bernabé

1964 [1653 ] Historia del Nuevo Mundo. Madrid, Biblioteca de Autores Españoles, Tomos 91-92.

Delhon, Claire

2005 Anthropisation et paléoclimats du Tardiglaciaire à l'Holocène en moyenne vallée du Rhône : études pluridisciplinaires des spectres phytolithiques et pédoanthracologiques de séquences naturelles et de sites archéologiques. Tesis doctoral, Université Paris 1, Panthéon-Sorbonne.

Delhon, Claire, Moutarde, Fanny, Tengberg, Margareta \& Thiebault, Stéphanie

2003 "Perceptions et représentations de l'espace à travers les analyses archéobotaniques". En Etudes Rurales, N¹67-168: 285-294.

Detienne, Pierre \& Jacquet, Paulette

1983 Atlas d'identification des bois de l'Amazone et des régions voisines. Nogent s/ Marne, Centre Technique Forestier Tropical.

Detienne, Pierre, Jacquet, Paulette, \& Mariaux, Alain

1982 Manuel d'identification des bois tropicaux. Nogent s/ Marne, Centre Technique Forestier Tropical.
Dulanto, Jahl

2001 "Dioses de pachacamac : el ídolo y el templo". In K. Makowski et al. (eds): Los dioses del Antiguo Perú,vol. 2. Lima : Banco de Crédito del Perú. p.159-181.

2002 "Pampa Chica: Prácticas de culto a los ancestros en la Costa Central del Perú". En Gaceta Arqueológica Andina 26:3767.

Eeckhout, Peter

2004 "Pachacamac y el proyecto Ychsma (1999-2003)". En Boletín del Instituto Francés de Estudios Andinos 33(3):425448.

Eeckhout Peter y Carlos Farfán

1999 Proyecto Ychsma. Investigaciones y estudios de restauraciones en el sitio de Pachacamac. Temporada 1 (1999) Excavación de la pirámide $\mathrm{N}^{\circ} 3$ de Pachacamac. Informe final.

Fauvet-berthelot Marie-France y Danièle Lavallée

1988 Ancien Pérou, vie, pouvoir et mort. Muséum National d'Histoire Naturelle, Musée de l'Homme : Exposition du Centenaire. Paris : Nathan.

Franco Jordan Régulo, Gálvez César y Segundo Vásquez

2001 "La Huaca Cao Viejo en el complejo El Brujo: una contribución al estudio de los Mochicas en el valle de Chicama". Arqueológicas, $\mathrm{N}^{\circ} 25$. Lima, Instituto de Investigaciones Antropológicas, Museo Nacional de Arqueología, Antropología e Historia del Perú, Instituto Nacional de Cultura. p.123-171.

Guaman Poma de Ayala, Felipe

1987 Nueva corónica y buen gobierno. Crónicas de América 29, 3 tomos. Madrid: Historia 16.

Jerez, Francisco de

1968[1534] "Verdadera relación de la conquista del Perú y provincia del Cuzco llamada la Nueva Castilla". In El Perú a través de los siglos. Primera serie. Tomo I. pp.191 - 
274. Editores Tecnicos asociados S.A., Lima.

Hastorf, Christine, A., \& Popper, Virginia, S.

1988 Current Paleoethnobotany : Analytical methods and cultural interpretation of archaeological plant remains. Chicago/London, The University of Chicago Press.

Hastorf, Christine, A., Whitehead, William, T. \& Johannessen, Sissel

2005 "Late prehistoric wood use in an andean intermontane valley". En Economic Botany, 59(4) : 337-355.

Johannessen, Sissel, \& Hastorf, Christine, A.

1990 "A History of fuel management (A.D. 500 to the present) in the Mantaro Valley, Peru". En Journal of Ethnobiology, $10: 61-90$.

Makowski Krzysztof

2002 "Arquitectura, estilo e identidad en el Horizonte Tardío: El sitio de PuebloViejo-Pucará, Valle de Lurín". En Boletín de Arqueología, PUCP 6:137170.

Marconetto, Maria, B.

2002 "Analysis of burnt building structures of the Ambato valley (Catamarca, Argentina)". En Charcoal Analysis. Methodological Approaches, Palaeoecological Results and Wood Uses. Proceedings of the Second International Meeting of Anthracology, Paris, September 2000, S. Thiébault (ed.), pp. 267-271. BAR International Series 1063, Oxford, England.

Moutarde, Fanny

2002 Première approche de la végétation ligneuse du Pérou précolombien: Mise en place d'un référentiel anthracologique à partir de la végétation côtière péruvienne actuelle. Application archéologique: Étude anthracologique du site de Pampa Chica (côte central, 1er millénaire BC). Diploma de Estudios Aprofundidos, Université Paris 1, Panthéon-Sorbonne.
2005 "La antracología aplicada a la arqueología peruana: Un análisis de los carbones provenientes de los fogones de Pampa Chica, valle de Lurin, 700-200 AC". En De l'Altiplano mexicain à la Patagonie Travaux et recherches à l'Université de Paris 1, pp.239-246. BAR S1389, Paris Monographs in American Archaeology 16. Oxford.

2006 L'évolution du couvert ligneux et de son exploitation par l'homme dans la vallée du Lurín (côte centrale du Pérou), de l'Horizon Ancien (900-100 av. J.-C.) à l'Horizon Tardif (1460-1532 apr. J.-C.) Aproche anthracologique. Tesis doctoral, Université Paris I, Panthéon-Sorbonne.

Paduano, Gina, M., Bush, Mark, B., Baker, Paul, A., Fritz, Sherilyn, C., \& Seltzer, Geoffrey, O.

2003 "A vegetation and fire History of Lake Titicaca since the Last Glacial Maximum". En Palaeogeography, Palaeoclimatology, Palaeoecology 194:259-279.

Pasiecznik, Nick, M., et al.

2001 The Prosopisjuliflora Prosopis pallida complex: A Monograph. Coventry, UK : HDRA.

Pearsall, Deborah, M.

1980 "Pachamachay ethnobotanical report: Plant utilization at a hunting base camp". En J. Rick, Prehistoric hunters of the high Andes, pp.191-231. New York : Academic Press.

1989 Paleoethnobotany: A handbook of procedures. San Diego, New York, Berkeley: Academic Press.

Petrequin, Pierre, \& Petrequin, Anne, M.

1992 "De l'espace actuel au temps archéologique ou les mythes d'un préhistorien". En Ethnoarchéologie: justification, problèmes, limites. XIIe Rencontres Internationales d'Archéologie et d'Histoire d'Antibes, pp.211-238. Juan-les-Pins : Editions APDCA. 
Pique Huerta, Raquél

2002 "Paisaje y explotación de recursos forestales entre los canoeros magallánicofueguinos. Aportación de la etnoarqueología”. En América Latina, historia y sociedad: una visión interdisciplinaria. Cinco años de Aula Oberta en la UAB, R. Piqué Huerta y M. Ventura i Oller (eds.), pp.77-94. Barcelona: Institut Català de Cooperació Iberoamericana/ Universitat Autònoma de Barcelona.

Raven, Peter, H., Evert, Ray, F. \& Eichhorn, Susan

2000 Biologie végétale. Traducción de la sexta edición americana. Paris, Bruxelles: DeBoeck University.

Reynel, Carlos \& Felipe-Morales, Carmen

1987 Agroforesteria tradicional en los Andes del Perú. Un inventario de tecnologías y especies para la integración de la vegetación leñosa a la agricultura. Lima, Proyecto FAO/Holanda/INFOR.

Rostworoski de Diez Canseco, María

1981 Recursos Naturales Renovables y Pesca Siglos XVI y XVII. Lima, Instituto de Estudios Peruanos.

2002 Pachacamac y el señor de los Milagros: Una trayectora milenaria. El Señorio de Pachacamac: El informe de Rodrigo Cantos de Andrade; Señorios indígenas de Lima y Canta. Obras completas II, Historia Andina 25. Lima, Instituto de Estudios Peruanos.

Rundell, Philipp, W., et al.

1991 "The phytogeography and ecology of the coastal Atacama and peruvian deserts".En Aliso 13 (1) : 1-49.

Santacruz Pachacuti Yanqui, don Juan de

1968[1613] "Relación de antigüedades deste reyno del Perú”. En Crónicas peruanas de interés indígena, F. Esteve Barba (ed.), pp.279-319. Biblioteca de autores españoles, 209. Madrid, Ediciones Atlas.

Scheel-Ybert, Rita

1998 Stabilité de l'écosystème sur le littoral sudest du Brésil à l'Holocène supérieur (5500.
1400 ans BP). Les pêcheurs-CueilleursChasseurs et le Milieu Végétal: Apports de l'Anthracologie. Tesis doctoral, Université Montpellier II Sciences et Techniques du Languedoc.

2002 "Evaluation of sample reliability in extant and fossil assemblages". En Charcoal Analysis. Methodological Approaches, Palaeoecological Results and Wood Uses. Proceedings of the Second International Meeting of Anthracology, Paris, September 2000. En S. Thiébault (ed.), pp. 9-16. BAR International Series 1063. Oxford, England.

Sherbondy, Jeannette, E.

1988 "Mallki - Ancestros y cultivo de arboles en los Andes". En R. Matos Mendieta (comp.) Sociedad andina: pasado y presente. Contribuciones en homenaje a la memoria de César Fonseca Martel, pp.101-135. Lima, Asociación Peruana para el fomento de las ciencias sociales, FOMCIENCIAS.

Shimada, Izumi

1985 "Perception, Procurement, and Management of Resources: Archaeological Perspectives". En I. Shimada y S. Masuda Andean (eds.) Ecology and Civilization, pp.357-399. Tokyo: University of Tokyo Press.

Solari, María, E.

1993 L'Homme et le bois en Patagonie et Terre de Feu au cours des six derniers millžnaires: recherches anthracologiques au Chili et en Argentine. Tesis doctoral, Université Montpellier II Sciences et Techniques du Languedoc

2000 "Antracología, Modo de Empleo: En torno a Paisajes, Maderas y fogones." En Revista Austral de Ciencias Sociales 4 : 167-174.

Tardy, Christophe

1998 Paléoincendies naturels, feux anthropiques et environnements forestiers de Guyane française $d u$ tardiglaciaire à l'holocène 
récent, approches chronologiques et anthracologiques. Tesis doctoral, Université Montpellier II Sciences et Techniques du Languedoc.

Taylor, Gérald

1980 Rites et traditions de Huarochiri : Manuscrit quechua du 17-ème siècle. Série ethnolinguistique amérindienne. Paris: Editions L'Harmattan.

Thiebault, Stéphanie (ed)

2002 Charcoal Analysis. Methodological Approaches, Palaeoecological Results and Wood Uses. Proceedings of the Second International Meeting of Anthracology, Paris, September 2000. BAR International Series 1063, Oxford, England.

Vernet, Jean L.

1973 "Etude sur l'histoire de la végétation du sud-est de la France au Quaternaire, d'après les charbons de bois principalement", En Paléobiologie Continentale 4(1) : 1-90.

Vernet, Jean L., Bazile, E., \& Evin, J.

1979 «Coordination des analyses anthracologiques et des datations absolues sur charbon de bois». En Bulletin de la Société Préhistorique Française 76(3):7679.

Walter, Doris

2002 L'alpiniste, le paysan et le Parc National du Huascaran. La domestication de la nature sauvage dans les Andes péruviennes. Tesis doctoral, Université Paris III Sorbonne Nouvelle, IHEAL.

Weberbauer, Augusto

1945 El mundo vegetal de los Andes peruanos. Lima : Ministerio de Agricultura.
Weir, Glendon H., \& Dering, Philipp

1986 "The lomas of Paloma, humanenvironment relationship in a central peruvian fog oasis: archaeobotany and palynology". En R. Matos Mendienta (ed.) Andean Archaeology, pp.18-44. Monographs in Anthropology, 27. Los Angeles : UCLA.

Western, A., C.

1963 "Wood and Charcoal in Archaeology". En D. Brothwell, E. Higgs \& G. Clark (eds.) Science in archaeology: a comprehensive survey of Progress and Research, pp.150-158. London : Thames \& Hudson.

Wheeler, Elizabeth, A., \& Baas, Pieter

1998 "Wood Identification-A Review". En IAWA Journal 19(3) : 241- 264.

Woods, William, I., Mccann, Joseph, M. \& Meyer, Donald, W.

2000 "Amazonian dark earth analysis : State of knowledge and directions for future research". En F. Andrew Schoolmaster (ed.) Papers and Proceedings of the Applied Geography Conferences, volume 23, pp.114-121. Texas: University of North Texas.

Zapata Peña, Lydia, Peña-chocarro, Leonor, Ibañez Estevez, Juan, J., Gonzalez Urquijo, Jesús, E. 2003 "Ethnoarchaeology in the Moroccan Jebale (Western Rif) : Wood and dung as fuel". En K. Neumann K., A. Butler \& S. Kahlheber (eds.) Food, Fuel and Fields, pp.163-175. Progress in African Archaeology. Monographs in African Archaeology and Environment, Africa Praehistorica 15. Köln: Heinrich Barth Institut. 